\title{
Aqueduct-100, A New Device and Method for Controllable Cervical Dilation
}

\author{
Larry Spiegelman, MD*, Ramon Sanchez-Rauder MD, and Cristina Travieso ARNP \\ Department of Gynecology, Baptist Medical Arts Surgical Center, Miami, Florida, USA
}

*Correspondence author: Larry Spiegelman, MD, Chief of Obstetrics and Gynecology, Baptist Hospital Miami Florida, 8950 North Kendall Drive, Suite \#302, Miami, Florida 33176; Tel: 305-595-4070; Email: larryspiegelman@gmail.com

Received: September 27, 2018; Accepted: October 05, 2018; Published: October 10, 2018;

\begin{abstract}
Objective

The aim of this investigation was to evaluate the effectiveness of the Aqueduct-100 for cervical dilation to a predetermined diameter in patients meeting eligibility criteria.

\section{Materials and Methods}

This modified cervical dilator (Aqueduct-100) is a triple balloon catheter with a diameter of $2.3 \mathrm{~mm}$ enabling a one-time insertion of the device into the cervical canal. After insertion through the vagina and into the endometrial cavity, the device was fixed in place and inflated. The dilating balloons remained inflated inside the cervix for one minute until dilation reliably reached the desired 5.0-5.5mm diameter. This study was conducted at the Obstetrics and Gynecology department at the principle investigator's surgical suite and Baptist Medical Arts Surgical Center, Miami, FL, USA from November 2016 through July 2017. The study included 30 patients ages 18 or older who were undergoing a diagnostic or operative hysteroscopy that required dilation.
\end{abstract}

\section{Results}

There were no reported problems operating the Aqueduct-100 mechanical dilator during the 29 reported procedures. In addition, the final diameter of the cervix after dilation was sufficient to perform the desired diagnostic/operative procedure without the need for further dilation by another method. Finally, the device was found to be user-friendly and adjustable to a patient's cervical anatomy through a gentle, radial force.

\section{Conclusion}

The results of the study suggest that Aqueduct-100 device can be used as an alternative for mechanical dilators to prevent uterine and cervical injuries during cervical dilation prior to diagnostic or operative hysteroscopy procedures.

Keywords: cervical incompetency; hysteroscopy; mechanical dilators; uterine perforation

\section{Introduction}

Cervical dilation allows sufficient access to the endometrial cavity when surgical instruments are required during an intrauterine procedure. Current dilation methods include hygroscopic or mechanical dilators, sometimes preceded by a pharmacological agent to ripen the cervix for dilation. $[1,2]$ These methods can be slow to work or involve multiple visits with the physician.[3] Moreover, if multiple insertions of the mechanical instruments are necessary during a single procedure, patients may require anesthesia for pain management, in addition to having an increased risk of infection, cervical or uterine lacerations, and intraperitoneal hemorrhages.[3, 4,5] Studies demonstrate the most frequently reported complications occurring during the dilation of the cervix prior to hysteroscopy are perforation and cervical trauma, with uterine perforation rates of approximately $0.7-0.8 \%$.[6] Risk factors associated with uterine perforation include cervical stenosis, severe uterine anteflexion or retroflexion, infection, myomas of lower uterine segments, and synechiae.[7] Furthermore, reports associate cervical trauma as a contributing factor for cervical insufficiency.[8]

Limitations associated with the methodology of current dilators include the inability to tailor the device to a patient's cervical anatomy or the unique requirements of each intrauterine procedure.[9] The functional inflexibility of current dilators may also exacerbate patient discomfort and increase the potential for injury endangering cervical integrity for future pregnancies, ie cervical incompetence.[4,5] To facilitate the mechanical methods for cervical dilation, we propose a cervical dilator based on a single act of insertion through the cervix, providing gradual and uniform dilation to a predetermined diameter within one minute, thereby reducing the risk of potential complications. 


\section{Material and Methods}

\section{Device Characteristics and Study Organization}

The modified cervical dilator (Aqueduct-100) used in this study is a triple-balloon catheter that dilates the cervix during a single act of insertion. The dimensions of the two dilating balloons (diameter and length) were selected to enable efficient dilation to all cervices ranging between 1 to $7 \mathrm{~cm}$. The outer diameter of the semi-rigid catheter is 7 French $(2.3 \mathrm{~mm})$, enabling easy insertion and manipulation of the catheter along the cervical canal. The consistency and endurance of the dilating balloons were tested previously to determine the breaching point for the Aqueduct-100. In vitro studies of the device revealed there was no detection of risk or breakage at a pressure of 14 bars. The reliability of these results was corroborated by an in vivo and ex vivo study reporting the ex-vivo mechanical response of the uterine cervix tissue did not differ considerably from what was observed in vivo. ${ }^{9}$ The study was conducted at the Obstetrics and Gynecology department at the principle investigator's surgical suite and Baptist Medical Arts Surgical Center, Miami, FL, USA from November 2016 through July 2017. The data were collected by the study coordinators in the operating room. An independent data and safety monitoring board monitored the study and reviewed the protocol compliance and outcome data. The protocol was approved by the institutional review board of Baptist Hospital, Miami, FL

\section{Study Patients}

Thirty patients were enrolled using the following inclusion criteria: (1) subjects were age 18 or older and (2) undergoing a diagnostic or operative hysteroscopy that required dilation. All patients enrolled signed an informed consent form. Each procedure was performed by the principle investigator and began with measurements of the cervix, uterine cavity, and diameter of the internal ostium (os). All patients underwent operative hysteroscopy under local anesthesia with conscious sedation. In all the patients where the cervix could be cannulated, the dilating balloons were inflated for exactly one minute.

\section{Procedure}

The initial diameter of the cervix was measured prior to the dilation procedure with the use of Hegar's rods. The catheter, with its balloons deflated (Fig. 1), was inserted through the vagina and the cervix into the endometrial cavity under sterile conditions. An anchoring balloon was inflated through the "Anchor channel" (Fig. 2) using a $2.5 \mathrm{ml}$ syringe with $1.5 \mathrm{ml}$ of bacteriostatic saline solution to fix the catheter in place. Two elongated dilating balloons were then inflated simultaneously at each end of the cervical canal (internal ostium and external ostium) by performing 3 consecutive injections of $2.5 \mathrm{ml}$ bacteriostatic saline solution through the "Dilation channel" (total volume of $7.5 \mathrm{ml}$ reaching an internal balloon pressure of 6 bars) (Fig. 2-3). The surgeon controlled the inflation rate, dilating the cervix gradually according to the resistance created by the cervix. The inflation of the dilating balloon required approximately 10 seconds, and the inflated balloons remained in the cervical canal for 1 minute. After the balloons were completely dilated, a bacteriostatic saline solution was injected into the cervical canal between the 2 dilating balloons through the "Infusion channel" to wash and lubricate the cervix. For catheter removal, all 3 balloons were deflated, and the catheter was removed in preparation for the intrauterine procedure. A final cervical diameter assessment was determined by measuring the dilation of the cervix prior to the intrauterine procedure. This measurement was confirmed by Hegar's rods.
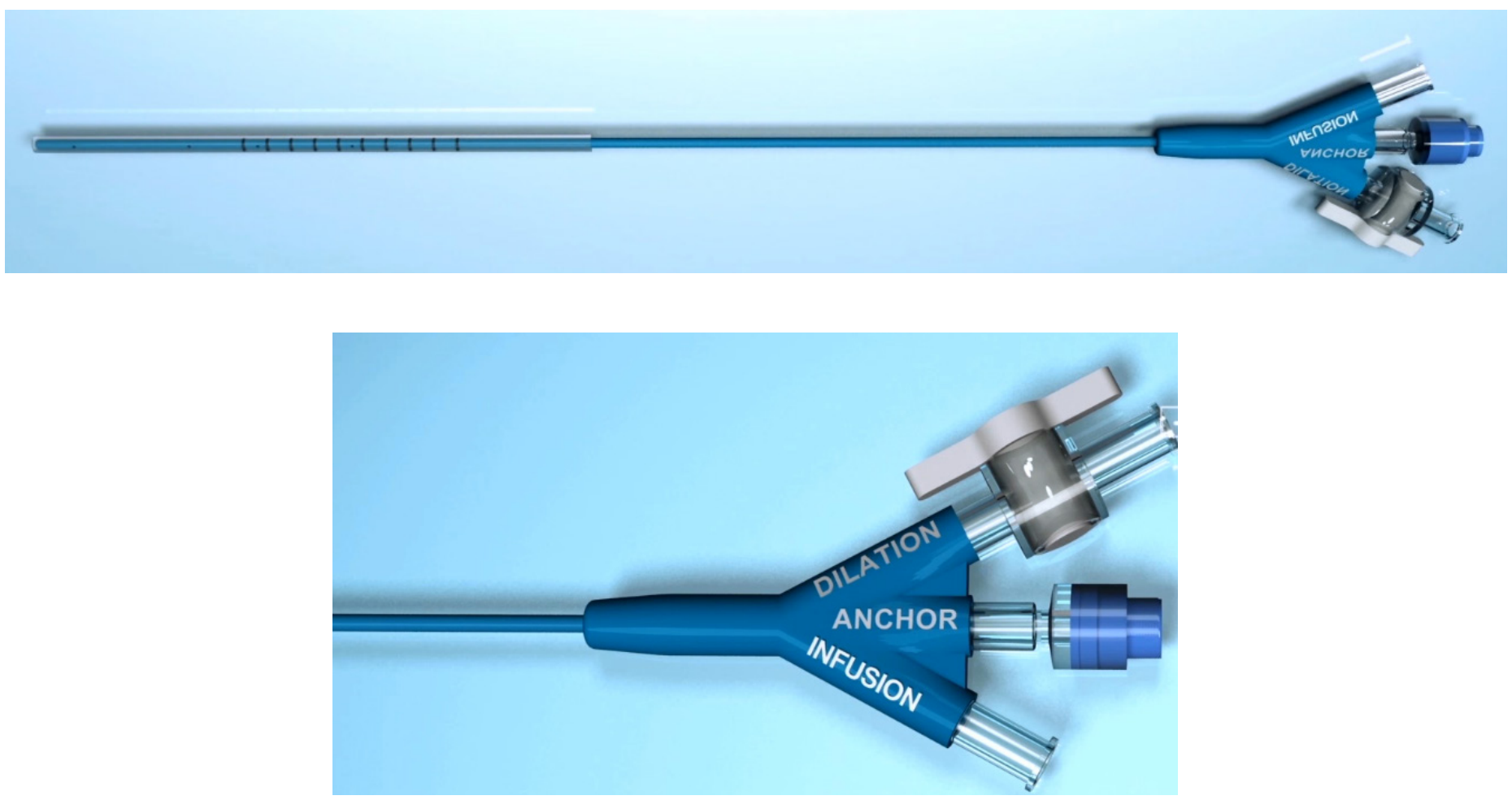


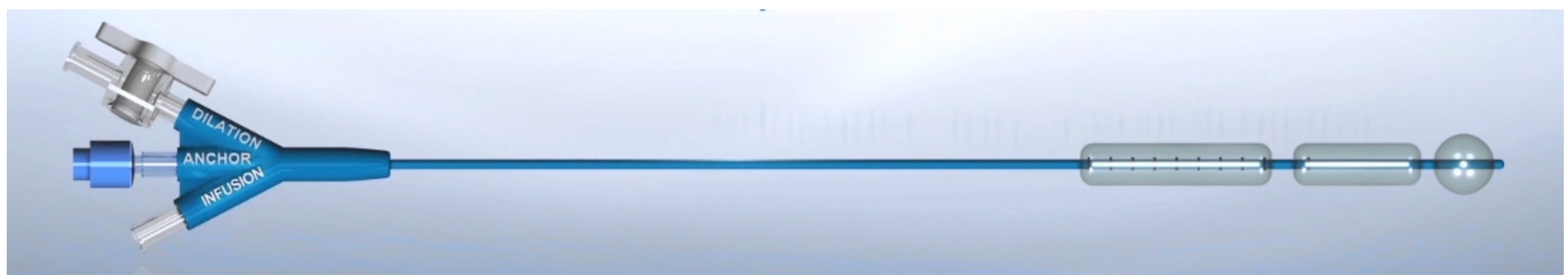

\section{Results}

The age of the 30 patients ranged from 29 to 59 , mean $(\mathrm{SD})=44.97$ \pm 8.08 . In one patient, the dilation could not be performed due to severe cervical stenosis after a previous LEEP cone biopsy. Although not excluded from the study, it was impossible to safely proceed with the procedure to any dilation without surgical intervention. For the remaining 29 patients, the initial diameter of the internal os was measured prior to each cervical dilation, and the final diameter of the internal os was measured at the end of the dilation procedure and prior to the intrauterine procedure as described in the methods (Table 1). In all patients, the final diameter of the cervix after dilation met the necessary diameter required to perform the diagnostic/operative procedure without the need for further dilation by another method.

Table 1. Initial and final diameter $(\mathrm{mm})$ of the cervices

\begin{tabular}{|c|c|c|c|}
\hline & $\begin{array}{c}\text { Number of } \\
\text { Patients (N) }\end{array}$ & $\begin{array}{c}\text { Mean } \\
\text { Diameter } \\
\mathbf{( m m )}\end{array}$ & $\begin{array}{c}\text { Standard } \\
\text { Deviation } \\
\text { (SD) }\end{array}$ \\
\hline Initial Measurement & 29 & 2.98 & 0.76 \\
\hline Final Measurement & 29 & 5.60 & 0.51 \\
\hline
\end{tabular}

The overall satisfaction of the physician was evaluated based on three categories: a) general ease of use, b) ease of insertion of the catheter along the cervix, and c) confidence with the procedure. The physician who carried out the dilation procedure recorded a score ranging between 1 to 4 for each category - $1=$ Unacceptable, $2=$ Difficult, 3 = Acceptable, and $4=$ Good. In all the 29 procedures performed, the doctor did not encounter problems operating the device and assigned the maximum score of 4 in all categories.

\section{Discussion}

Based on our results, the Aqueduct-100 may be a replacement for traditional mechanical cervical dilators when considering the prevention of uterine and/or cervical injury. Advantages of this cervical dilator include: a demonstrated single act of insertion of the device through the cervix and adjustability of the device to fit the needs of the surgeon during a variety of diagnostic or operative hysteroscopies requiring dilation. The advantages of Aqueduct-100 compared to traditional mechanical dilators are summarized in Table 2.

Understanding cervical resistance is central to ensuring patient safety when dilating a cervix through mechanical instruments. Excessive force can lead to cervical or uterine injury, including bleeding, lacerations, and perforations.[3,4,5] According to a recent study, Arsenijevic et al. reported cervical resistance was depressed after 23 seconds with a pressure of 3.8 bars when using a continuous controllable balloon dilator.[2] In comparison, the two dilating balloons of the Aqueduct-100 generated a pressure of 6 bars during 10 seconds of dilation to overcome the resistance of the cervix. By inflating the dilating balloons through three consecutive injections of $2.5 \mathrm{ml}$ of saline, the cervix was dilated radially and gradually. The inflated balloons remained inside the cervix for one minute, to allow the cervical walls time to adjust to the radial forces. Moreover, during the dilation period saline was injected between the dilating balloons to wash and lubricate the cervical canal. Injecting saline between the dilating balloons washes and cleans the cervix from bloody mucus thus providing a clean cervix prior to insertion of the hysteroscope and reducing the risk of infection.

Table 2. Comparison of Aqueduct-100 to mechanical dilators

\begin{tabular}{|l|l|l|}
\hline \multicolumn{1}{|c|}{ Feature } & \multicolumn{1}{|c|}{ Mechanical dilators ${ }^{1-5}$} & \multicolumn{1}{c|}{ Aqueduct-100 } \\
\hline $\begin{array}{l}\text { Duration of dilation } \\
\text { procedure }\end{array}$ & $\begin{array}{l}\text { Approximately one } \\
\text { minute }\end{array}$ & One minute \\
\hline $\begin{array}{l}\text { Number of insertions } \\
\text { required }\end{array}$ & Multiple & One \\
\hline $\begin{array}{l}\text { Forcefulness of dilation } \\
\text { procedure }\end{array}$ & High direct force & Gentle radial force \\
\hline $\begin{array}{l}\text { Ability to adapt } \\
\text { to unique cervical } \\
\text { anatomies }\end{array}$ & $\begin{array}{l}\text { Highly dependent on the } \\
\text { skill of the physician }\end{array}$ & $\begin{array}{l}\text { Adaptation to cervical } \\
\text { anatomies built into the } \\
\text { product design (semi- } \\
\text { rigid shaft) }\end{array}$ \\
\hline $\begin{array}{l}\text { Risk of injury due to } \\
\text { false route, perforation }\end{array}$ & $\begin{array}{l}\text { Highly dependent on the } \\
\text { skill of the physician }\end{array}$ & Very low \\
\hline $\begin{array}{l}\text { Risk of cervical } \\
\text { incompetence }\end{array}$ & Present & Very low \\
\hline
\end{tabular}

1. Gupta JK, Johnson N. Should we use prostaglandins, tents or progesterone antagonists for cervical ripening before first trimester abortion? Contraception. 1992; 46(5): 489-497.

2. Biron-Shental T, Fishman A, Fejgin MD. Medical and mechanical methods for cervical ripening. Int J Gynaecol Obstet. 2004; 85(2): 159-160.

3. Lichtenberg ES, Paul M, Jones H. First trimester surgical abortion practices: a survey of national abortion federation members. Contraception. 2001; 64(5): 385-392.

4. Gelber S, Sciscione A: Mechanical methods of cervical ripening and labor induction. Clin Obstet Gynecol 2006, 49: 642-657.

5. Iams J D. Philadelphia, PA: Elsevier Inc; 2009. Cervical insufficiency; p. 586.

A previous study with the Aqueduct-100 cervical dilator was conducted in the department of Gynecology, Hospital General Santa María del Puerto, Cádiz, Spain.[10] Fifty patients were divided into 2 groups. Group A $(n=38)$ underwent cervical dilation while the dilating balloons remained inflated inside the cervix for five minutes and Group B ( $\mathrm{n}=12)$ underwent cervical dilation while the dilating balloons remained inflated inside the cervix for 3 minutes. The average 
initial diameter of the cervix of Group A was $3.0 \pm 1.0 \mathrm{~mm}$ and in Group $\mathrm{B}, 2.2 \pm 0.6 \mathrm{~mm}(\mathrm{P}=0.0220)$. The final diameter was $8.1 \pm 1.1 \mathrm{~mm}$ and $6.4 \pm 0.8 \mathrm{~mm}$ respectively $(\mathrm{P}<0.0001)$. The results demonstrated the correlation between the duration of the dilation process and the final diameter of the dilated cervix, ie the ability to dilate the cervix to a pre-determined diameter by controlling the duration of the process. This finding has practical significance. The 3-minute dilation process can be implemented in procedures that require a cervical diameter approximately $6.5 \mathrm{~mm}$ and the 5 -minute dilation process can be implemented in procedures that require approximately an $8-9 \mathrm{~mm}$ cervical dilation, such as in hysteroscopic myomectomy and dilation and evacuation (D\&E) procedures.

\section{Conclusion}

In our present study, the dilating balloons remained inflated inside the cervix for 1 minute to dilate the cervix to the desired $5.0-5.5 \mathrm{~mm}$ in diameter required to successfully perform each of the hysteroscopy procedures. In all cases that the cervix could be cannulated, the cervix was successfully dilated to the minimal diameter required to at least perform the hysteroscopic procedures using a $5 \mathrm{~mm}$ operative hysteroscope. Moreover, there was no difficulty reported upon inserting a $6 \mathrm{~mm}$ operative device for a bipolar ablation procedure.

Current dilators do not have the ability to adjust to meet the needs of the unique cervical anatomy/physiology and procedural requirements of each patient. Because of this, patient discomfort and the risk of injury is increased, endangering cervical integrity for future pregnancies. Considering our findings, the Aqueduct-100 device may be used as an alternative to mechanical dilators with decreased risk of uterine and cervical injuries during cervical dilations. It is important to emphasize that due to the limited number of participants enrolled in this study, a further prospective study may be required to achieve the power to validate the effectiveness of Aqueduct-100 cervical dilator.

\section{Acknowledgements}

The authors would like to thank Andrew O. Idowu, MD, MBA for his assistance with analgesia during the surgical procedures.

\section{Disclosure Statements}

Larry Spiegelman declares no conflict of interest.

Ramon Sanchez-Rauder declares no conflict of interest.

Cristina Travieso declares no conflict of interest.

\section{References}

1. Allen RH, Goldberg AB (2016) Cervical dilation before first-trimester surgical abortion (<14 weeks' gestation). Contraception. 93(4): 277-291. [Crossref]

2. Arsenijevic S, Vukcevic-Globarevic G, Volarevic V, Macuzic I, Todorovic P, Tanaskovic I, et al. (2012) Continuous controllable balloon dilation: a novel approach for cervix dilation. Trials. 13: 196. [Crossref]

3. Gupta JK, Johnson N (1992) Should we use prostaglandins, tents or progesterone antagonists for cervical ripening before first trimester abortion? Contraception. 46(5): 489-497. [Crossref]

4. Gelber S (2006) Sciscione A: Mechanical methods of cervical ripening and labor induction. Clin Obstet Gynecol. 49: 642-657. [Crossref]

5. Jansen FW, Vredevoogd CB, van Ulzen K, Hermans J, Trimbos JB, TrimbosKemper TC. (2006) Complications of hysteroscopy: a prospective, multicenter study. Obstet Gynecol. 49: 642-657. [Crossref]
6. Loffer FD (1995) Contraindications and complications of hysteroscopy. Obstet Gynecol Clin North Am. 22(3): 445-455. [Crossref]

7. Iams J D (2009) Philadelphia, PA: Elsevier Inc; Cervical insufficiency; p. 586

8. Leppert PC (1995) Anatomy and physiology of cervical ripening. Clin Obstet Gynecol. 38(2): 267-279. [Crossref]

9. Mazza E, Nava A, Bauer M, Winter R, Bajka M, Holzapfel GA (2006) Mechanical properties of the human uterine cervix: an in vivo study. Med Image Anal. 10(2): 125-36. [Crossref]

10. Vico de Miguel FJ, Pantoja-Garrido M, Frias-Sanchez Z, Pantoja-Rosso FJ, Martins E, Weichselbaum A (2017) Experience with a device for controlled cervical dilation. Ginecol Obstet Mex. 85(3): 125-133.

\section{Citation:}

Larry Spiegelman, Ramon Sanchez-Rauder and Cristina Travieso (2018) Aqueduct-100, A New Device and Method for Controllable Cervical Dilation. J Clin Res Med Volume 1(3): 1-4. 